\title{
Spontaneous Development of Acute Obstructive Suppurative Pancreatic Ductitis Associated with Pancreatic Carcinoma: A First Case Report
}

\author{
Kunio Iwatsuka ${ }^{1}$, Hiroshi Nakagawara ${ }^{1}$, Masahiro Ogawa ${ }^{1}$, Takuji Gotoda ${ }^{1}$, \\ Shigeoki Hayashi ${ }^{2}$, Noriko Kinukawa ${ }^{3}$, Akihiro Hemmi ${ }^{3}$, Kenji Yamao ${ }^{4}$, \\ Akio Yanagisawa ${ }^{5}$ and Mitsuhiko Moriyama ${ }^{1}$
}

\begin{abstract}
:
A 68-year-old man with a history of diabetes mellitus was admitted to our hospital with a diagnosis of acute pancreatitis. Abdominal computed tomography revealed a suspicious tumor in the body of the pancreas, along with a dilated main pancreatic duct and edema of the pancreatic tail. Endoscopic retrograde pancreatography was performed after treating the patient's pancreatitis. When a cannula tip was advanced beyond the stenosis, deep into the distal pancreatic duct, thick white pus was evacuated. A bacteriological examination of the aspirated pancreatic juice revealed Enterobacter cloacae, and a cytological examination revealed adenocarcinoma. The diagnosis was acute obstructive suppurative pancreatic ductitis associated with pancreatic carcinoma.
\end{abstract}

Key words: acute obstructive suppurative pancreatic ductitis, main pancreatic duct obstruction, bacterial infection, pancreatic carcinoma

(Intern Med 57: 1241-1245, 2018)

(DOI: 10.2169/internalmedicine.9862-17)

\section{Introduction}

Acute obstructive suppurative pancreatic ductitis (AOSPD) is a rare disease defined as suppuration in the main pancreatic duct (MPD) without associated pseudocyst, abscess, or necrosis. It is a counterpart of acute obstructive suppurative cholangitis in the biliary tract. Weinman reported the first case in 1995 (1). A history of chronic pancreatitis (CP) or prior ampullary procedure [e.g., endoscopic sphincterectomy (EST) or endoscopic retrograde pancreatography (ERP)], as well as pancreatic ductal obstruction, are considered necessary for the development of AOSPD (1-11). This case was considered unique because it was a rare case of spontaneous AOSPD associated with pancreatic ductal obstruction caused by pancreatic carcinoma in a patient without a history of $\mathrm{CP}$ or a previous ampullary procedure. To the best of our knowledge, there are no case reports of AOSPD with a similar pathogenesis.

\section{Case Report}

A 68-year-old man with a history of type 2 diabetes mellitus (from 62 years of age) was referred to our hospital with complaints of subsequent epigastric and back pain, and a fever of $38.1^{\circ} \mathrm{C}$. He had been smoking for 40 years but did not drink alcohol. Laboratory blood tests revealed a white blood cell count of $11,300 / \mu \mathrm{L}$ (reference range, 3,5009,000 cells $/ \mathrm{mm}^{3}$ ), a C-reactive protein concentration of 14.52 $\mathrm{mg} / \mathrm{dL}$ (reference range, $<0.30 \mathrm{mg} / \mathrm{dL}$ ), and serum amylase concentration of $350 \mathrm{IU} / \mathrm{L}$ (reference range, 40-130 IU/L). With regard to diabetes mellitus, fasting blood sugar level

\footnotetext{
${ }^{1}$ Division of Gastroenterology and Hepatology, Nihon University School of Medicine, Japan, ${ }^{2}$ Department of Digestive Surgery, Nihon University School of Medicine, Japan, ${ }^{3}$ Division of Pathology, Nihon University School of Medicine, Japan, ${ }^{4}$ Department of Gastroenterology, Narita Memorial Hospital, Japan and ${ }^{5}$ Department of Pathology and Laboratory Medicine, Kyoto First Red Cross Hospital, Japan Received: July 22, 2017; Accepted: September 8, 2017; Advance Publication by J-STAGE: December 27, 2017 Correspondence to Dr. Hiroshi Nakagawara, nakagawara.hiroshi@nihon-u.ac.jp
} 


\section{B}
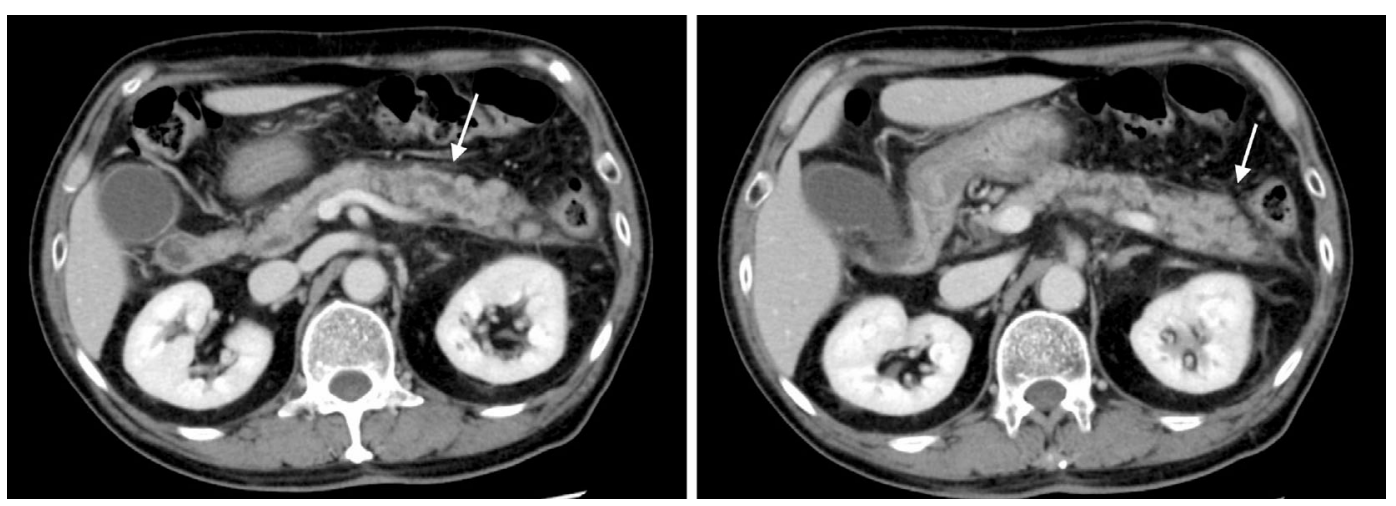

Figure 1. Contrast CT. (A) MPD stricture in the body of the pancreas, along with a markedly dilated MPD in the pancreatic tail (arrow). (B) The edematous pancreatic tail with peripancreatic inflammatory changes (arrow).

A

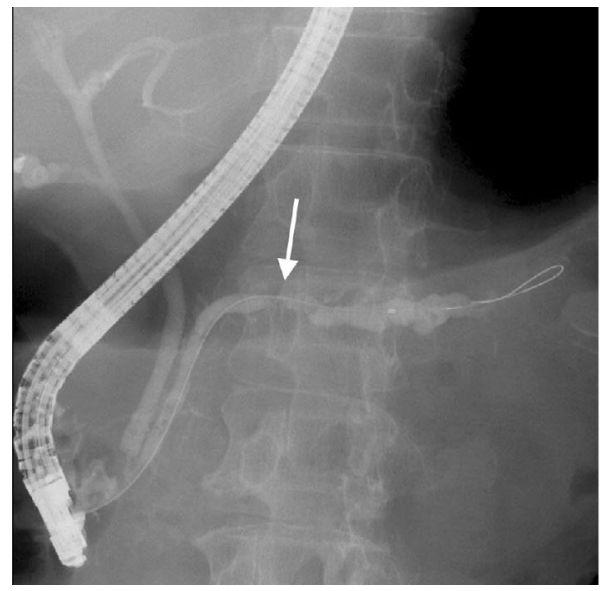

B

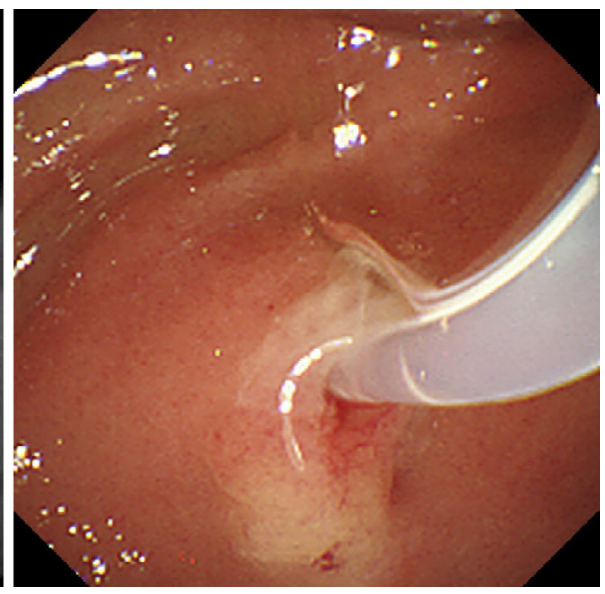

Figure 2. Endoscopic retrograde pancreatography. (A) A 10-mm-long stricture in the MPD, along with a markedly dilated MPD in the pancreatic tail. (B) Thick white pus was evacuated when a cannula tip was advanced deep into the distal pancreatic duct.

was $134 \mathrm{mg} / \mathrm{dL}$ (reference range, 70-110 mg/dL), and his hemoglobin A1c concentration was $7.1 \%$ (reference range, 4.7-6.2\%). His carcinoembryonic antigen 19-9 level was 85.4 IU/mL (reference range, $<37 \mathrm{U} / \mathrm{mL}$ ). Computed tomography (CT) showed a suspicious tumor in the body of the pancreas with a markedly dilated main pancreatic duct (MPD) (Fig. 1A), and an edematous parenchyma with peripancreatic inflammatory changes limited to the tail of the pancreas (Fig. 1B). CT and magnetic resonance cholangiopancreatography demonstrated slight dilation of the major ampulla-side MPD, $3 \mathrm{~mm}$ from the obstruction. However, there were no findings of $\mathrm{CP}$ (e.g., irregular MPD contour, dilated side branch, intraluminal protein plug). We did not detect abscess, pseudocyst, or calcification in the pancreas. The patient was admitted to our hospital with an initial diagnosis of acute obstructive pancreatitis caused by pancreatic carcinoma.

The patient was treated for acute pancreatitis (AP) with fluid resuscitation, antibiotics (meropenem hydrate $0.5 \mathrm{~g}, 3$ times/day) and a protease inhibitor [gabexate mesilate (300 mg, twice daily)]. The patient's symptoms resolved on the eighth day after admission. Laboratory blood tests showed a reduced white blood cell count $(7,900 / \mu \mathrm{L})$ and serum amylase (102 IU/L); however, the patient's C-reactive protein level remained high $(4.54 \mathrm{mg} / \mathrm{dL})$.

On the ninth day after admission, we performed ERP to investigate the cause of the MPD obstruction. When a cannula tip was advanced beyond the stenosis deep into the distal MPD (Fig. 2A), thick white pus was evacuated (Fig. 2B). A bacteriological examination and aspirate culture revealed Enterobacter cloacae. A 5-Fr endoscopic nasopancreatic drainage (ENPD) tube was placed, and a cytological examination of the pancreatic juice revealed pancreatic adenocarcinoma. Two days after ENPD catheter placement, we confirmed that the pancreatic juice was clear. We therefore removed the ENPD catheter. Over a two-day period, the total volume of pancreatic juice output from the ENPD catheter was $335 \mathrm{~mL}$. On the 23rd day after admission, he was discharged from hospital without an exacerbation of the symptoms. 
A

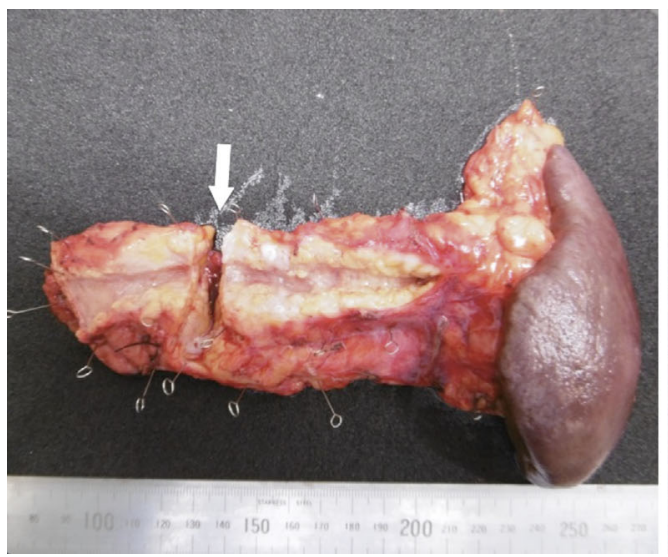

B

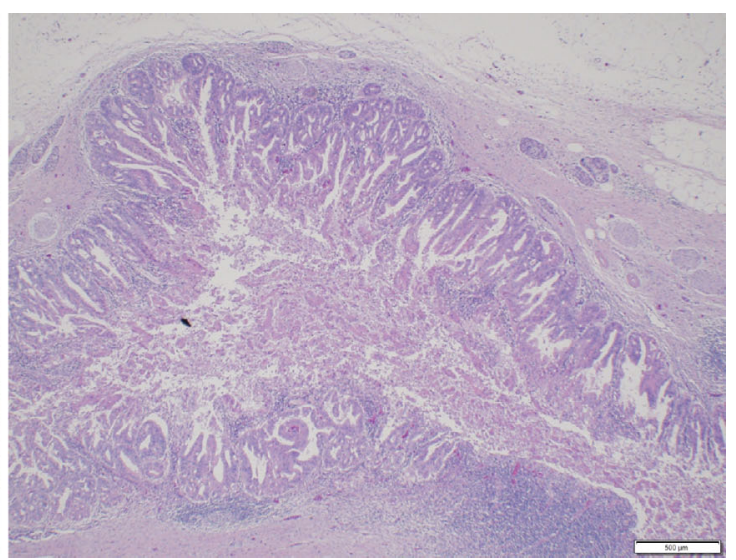

Figure 3. The gross and histological findings. (A) The gross findings of the resected specimen. The stricture of the MPD was seen in the body of the pancreas (arrow). The carcinoma was unclear in the gross examination. (B) The histological examination. Adenocarcinoma was recognized. Most of the carcinoma, including the MPD stricture was in situ. Interstitial microinvasion was seen in places, with only a low level of fibrosis in the pancreatic parenchyma associated with intestinal invasion.

Sixteen days after being discharged from our hospital, he was readmitted and pancreaticoduodenectomy was performed. As a result, an invasive ductal carcinoma of $\sim 5 \mathrm{~cm}$ in size was identified in the body of the MPD (Fig. 3A). A pathological examination revealed that most of the adenocarcinoma, including the MPD stricture, was in situ. Pancreatic parenchymal microinvasion was seen in places (Fig. 3B), especially around the MPD stricture. There was a low level of pancreatic parenchymal fibrosis associated with the parenchymal invasion of the carcinoma. The obstruction of the MPD was caused by part of the carcinoma in situ with papillary growth. The papillae were short in height, unlike the long papillae (so-called finger-like papillae) found in intraductal papillary mucinous neoplasms; rich mucin production was not seen. Thus, the carcinoma was diagnosed as a papillary adenocarcinoma, but not intraductal papillary mucinous carcinoma. Neutrophilic infiltration was seen in the dilated MPD lumen of the pancreatic tail, and in the pancreatic stromal tissue around the dilated MPD of the pancreatic tail. Finally, we made a diagnosis of AOSPD caused by an MPD obstruction resulting from pancreatic carcinoma.

\section{Discussion}

Although no fatal cases of AOSPD have been reported, it frequently causes septic shock $(2,5-7,10,11)$. In the present case antibiotics resulted in an improvement of the patient's condition; however, several reports have described cases in which antibiotic treatment failed (1-3, 6-8, 11). For this reason, when AOSPD is suspected, the rapid drainage of the pancreatic duct with endoscopic intervention is desirable. However, most of the reported cases of AOSPD were initially misdiagnosed and treated as mild AP $(2,4)$ or acuteon-CP $(1,3,6-8)$. It is difficult to differentiate AOSPD from AP and acute-on-CP, because there are no significant differ- ences in their clinical features, imaging findings, or laboratory findings. Thus far, 29 cases of AOSPD have been reported. Among them, CT showed mild AP (e.g., parenchymal enlargement, expanded attenuation of the surrounding fat, fluid collection) in seven cases $(24.1 \%)(2,4,6,8,9$, 11 ), and $\mathrm{CP}$ (e.g., parenchymal atrophy, pancreatic stone) in 11 cases $(36.7 \%)(1,3,5,7,11)$. The serum amylase level, which was documented in 26 cases, was reported to be almost normal or only slightly elevated $(2,4,8,9,11)$. The main focus of the inflammation was thought to be the MPD rather than the pancreatic parenchyma, unlike in AP. The serum $\mathrm{C}$-reactive protein (CRP) level was markedly high ( $>10$ $\mathrm{mg} / \mathrm{dL})$ in $12(50.0 \%)$ of 24 cases in which it was documented $(2,4,6,8,10,11)$. This may reflect inflammation of the MPD in AOSPD. AOSPD should be considered when CT findings of MPD obstruction along with a dilated MPD and signs of mild pancreatitis limited to the distal pancreas are observed along with the characteristic laboratory data (a markedly elevated serum CRP level, and a roughly normal to slightly elevated serum pancreatic amylase level).

The hypothesized pathogenesis of AOSPD is as follows. MPD obstruction causes pancreatic juice stasis, but it does not usually cause suppurative ductitis, similar to the cause of acute obstructive suppurative cholangitis. Normally, pancreatic juice has a significant degree of antibacterial activity (12). In addition to MPD obstruction, the following features are considered to be risk factors for AOSPD: alcohol consumption, smoking, diabetes mellitus, immune dysfunction, a history of $\mathrm{CP}$, or a prior ampullary procedure (11). Almost all previous cases of AOSPD had either a history of $\mathrm{CP}$ or an ampullary procedure. Thus, these two factors are considered to be essential for its development. $\mathrm{CP}$ is thought to contribute to the development of ASOPD because the pancreatic juice from patients with $\mathrm{CP}$ has impaired antibacterial activity (12). A prior ampullary procedure is thought 
Table. Prior AOSPD Cases without Previous Ampullary Procedure (Endoscopic Sphincterectomy or Endoscopic Retrograde Pancreatography).

\begin{tabular}{|c|c|c|c|c|c|c|c|c|c|c|}
\hline Reference & $\begin{array}{c}\text { Age/ } \\
\text { Gender }\end{array}$ & $\begin{array}{l}\text { Relevant } \\
\text { comorbid } \\
\text { conditions }\end{array}$ & Alcohol & Smoking & $\mathrm{DM}$ & $\begin{array}{l}\mathrm{BT} \\
\left({ }^{\circ} \mathrm{C}\right)\end{array}$ & $\begin{array}{l}\text { WBC } \\
(/ \mu \mathrm{L})\end{array}$ & $\begin{array}{c}\text { CRP } \\
(\mathrm{mg} / \mathrm{dL})\end{array}$ & $\begin{array}{l}\text { Serum } \\
\text { amylase } \\
(\mathrm{U} / \mathrm{L})\end{array}$ & CT scan findings \\
\hline 6) & 53/male & $\begin{array}{c}\mathrm{CP} \\
\text { leukemia }\end{array}$ & ND & ND & No & $\begin{array}{l}\text { High } \\
\text { fever } \\
\text { (ND) }\end{array}$ & 3,190 & 12.1 & $\begin{array}{c}\text { Normal } \\
\text { level } \\
\text { (ND) }\end{array}$ & $\begin{array}{l}\text { pancreatic stones, paren- } \\
\text { chymal enlargement, fluid } \\
\text { collection }\end{array}$ \\
\hline 8) & 50/male & $\mathrm{CP}$ & Yes & Yes & No & 38.5 & 5,700 & 11.2 & 1,382 & parenchymal enlargement \\
\hline 10) & 60 s/male & IPMC & Yes & Yes & Yes & 38.0 & 12,300 & 16.2 & 31 & parenchymal atrophy \\
\hline \multicolumn{11}{|l|}{ 11) } \\
\hline \multirow[t]{3}{*}{4 cases } & $62 / \mathrm{male}$ & $\mathrm{CP}$ & Yes & Yes & No & 38.5 & 17,200 & 26.0 & 33 & pancreatic stones \\
\hline & $52 /$ male & $\mathrm{CP}$ & Yes & Yes & No & 38 & 12,500 & 10.6 & 256 & pancreatic stones \\
\hline & 41/male & $\mathrm{CP}$ & Yes & Yes & No & 37.1 & 12,100 & 3.1 & 133 & parenchymal atrophy \\
\hline Present case & $62 /$ male & $\mathrm{DM}$ & No & Yes & Yes & 38.1 & 11,300 & 14.5 & 350 & $\begin{array}{c}\text { parenchymal enlargement, } \\
\text { expanded attenuation of } \\
\text { surrounding fat }\end{array}$ \\
\hline
\end{tabular}

DM: diabetes mellitus, BT: body temperature, WBC: white blood cell, CRP: C-reactive protein, CT: computed tomography, CP: chronic pancreatitis, ND: not determined, IPMN: intraductal papillary mucinous neoplasm, IPMC: intraductal papillary mucinous neoplasm

to cause the reflux of bacteria from the gastrointestinal tract into the MPD though the injection of contrast material, guide wire insertion, or dysfunction of the papilla of Vater after EST. The characteristics of the previous cases of AOSPD in patients who had no history of a previous ampullary procedure are shown in Table. With the exception of one case (10), all of the AOSPD patients without a history of a previous ampullary procedure had a history of $\mathrm{CP}$. The one exception showed a different pathogenesis from the other cases, in that intraductal papillary mucinous carcinoma caused the formation of a pancreatobiliary fistula, resulting in the development of a hepatic abscess and AOSPD (10).

The combination of pancreatic juice stasis with the reflux of bacteria into the MPD, an ampullary procedure or impaired antibacterial activity of the pancreatic juice, and $\mathrm{CP}$ is expected to cause uncontrolled bacterial proliferation.

Among the 29 previously reported cases of AOSPD, most MPD obstruction was caused by $\mathrm{CP}$ and pancreatic stones $(1,3,5-9,11)$. Only four cases of AOSPD were associated with MPD obstruction caused by pancreatic carcinoma $(2,4,11)$. In addition, all four of those cases had previously undergone EST or ERP. Our present case was unique in that it involved spontaneous AOSPD associated with MPD obstruction caused by pancreatic carcinoma, without a history of $\mathrm{CP}$ or a prior ampullary procedure.

In our case, the risk factors for AOSPD included smoking and diabetes mellitus. The exact pathogenesis of our case of AOSPD was unclear. However, diabetes mellitus might have contributed because it predisposes the patient to infection, and causes exocrine cell exhaustion, which may lead to the impairment antibacterial activity of pancreatic juice, as oc- curs in $\mathrm{CP}$.

In conclusion, we herein reported a case of AOSPD associated with pancreatic carcinoma without a history of $\mathrm{CP}$ or an ampullary endoscopic procedure. To the best of our knowledge, there have been no previous reports of AOSPD with a similar pathogenesis. Further similar case reports should be collected to provide more information about the pathogenesis of this rare clinical entity.

The authors state that they have no Conflict of Interest (COI).

\section{References}

1. Weinman DS. Acute suppuration of the pancreatic duct. Gastrointest Endosc 41: 268-270, 1995.

2. Tajima Y, Kuroki T, Susumu S, et al. Acute suppuration of the pancreatic duct associated with pancreatic ductal obstruction due to pancreas carcinoma. Pancreas 33: 195-197, 2006.

3. Wali E, Koo P, Packer CD. Acute obstructive suppurative pancreatic ductitis in an asymptomatic patient. Case Rep Med 2015: 919452, 2015.

4. Isono Y, Matsusaki S, Tanaka H, et al. Acute obstructive suppurative pancreatic ductitis after endoscopic retrograde cholangiopancreatography in a patient with carcinoma of the pancreatic head: a case report. Nihon Shokakibyo Gakkai Zasshi 113: 289-295, 2016 (in Japanese, Abstract in English).

5. Tollivoro T, Palakodeti S, Munroe C. Acute obstructive suppurative pancreatic ductitis. ACG Case Rep J 3: e136, 2016.

6. Fujimori N, Igarashi H, Ito T. Acute obstructive suppurative pancreatic ductitis. Clin Gastroenterol Hepatol 9: A28, 2011.

7. Deeb L, Bajaj J, Bhargava S, Alcid A, Pitchumoni CS. Acute suppuration of the pancreatic duct in a patient with tropical pancreatitis. Case Rep Gastroenterol 2: 27-32, 2008.

8. Aoki S, Okayama Y, Hayashi K, et al. A case of purulent pancre- 
atic ductitis successfully treated by endoscopic stenting. Digestive Endoscopy 12: 341-344, 2000.

9. Fujinaga T, Nishida T, Miyazaki M, et al. Acute suppurative pancreatic ductitis associated with pancreatic duct obstruction. Endoscopy 45 (suppl 2 UCTN): E135, 2013.

10. Nishie H, Okumura F, Fukusada S, et al. A case of intraductal papillary mucinous carcinoma found with acute obstructive suppurative pancreatic ductitis and liver abscess, and associated with a pancreatobiliary fistula. Nihon Shokakibyo Gakkai Zasshi 110: 1304-1312, 2013 (in Japanese, Abstract in English).
11. Kondo H, Naitoh I, Okumura F, et al. Clinical features of acute obstructive suppurative pancreatic ductitis: A retrospective review of 20 cases. J Gastroenterol Hepatol 31: 1366-1373, 2016.

12. Marotta F, Tajiri H, Li ZL, Barreto R, Bellini O, Barbi G. Pure pancreatic juice from patients with chronic pancreatitis has an impaired antibacterial activity. Int J Pancreatol 22: 215-220, 1997.

The Internal Medicine is an Open Access article distributed under the Creative Commons Attribution-NonCommercial-NoDerivatives 4.0 International License. To view the details of this license, please visit (https://creativecommons.org/licenses/ by-nc-nd/4.0/).

(C) 2018 The Japanese Society of Internal Medicine Intern Med 57: 1241-1245, 2018 